exhibit insufficient volume, a microvascular muscle flap is probably the best treatment option for reconstruction of a large thoracic dead space. The vastus lateralis muscle represents an ideal choice because its distal location allows simultaneous flap harvest and recipient site preparation. A large bulk can be provided to totally obliterate the space around the prosthetic graft, and there is minimal dysfunction of the lower limb after removal of the muscle. ${ }^{1}$

In conclusion, a 2-stage procedure with an open-window thoracostomy, followed by a microvascular muscle flap, might be of value to treat severe intrathoracic infection around aortic prosthetic grafts in high risk patients.

\section{References}

1. Chen HC, Santamaria E, Chen HH, Cheng MH, Chang CJ, Tang YB. Microvascular vastus lateralis muscle flap for chronic empyema associated with a large cavity. Ann Thorac Surg. 1999;67:866-9.

2. Muller BT, Wegener OR, Grabitz K, Pillny M, Thomas L, Sandmann $\mathrm{W}$. Mycotic aneurysms of the thoracic and abdominal aorta and iliac arteries: experience with anatomic and extra-anatomic repair in 33 cases. J Vasc Surg. 2001;33:106-13.

3. Hsu RB, Tsay YG, Wang SS, Chu SH. Management of aortic aneurysm infected with Salmonella. Br J Surg. 2003;90:1080-4.

4. Nakamura Y, Kawachi K, Imagawa H, Watanabe Y, Hamada Y, Tsunooka N. Mycotic aneurysm of the aortic arch due to Salmonella. Jpn J Thorac Cardiovasc Surg. 2003;51:253-5.

\title{
Novel knot-tying technique for mitral valve repair
}

Hironori Izutani, MD, PhD, Masao Yoshitatsu, MD, PhD, Jyun Kawamoto, MD, and Keijiro Katayama, MD, Hiroshima, Japan

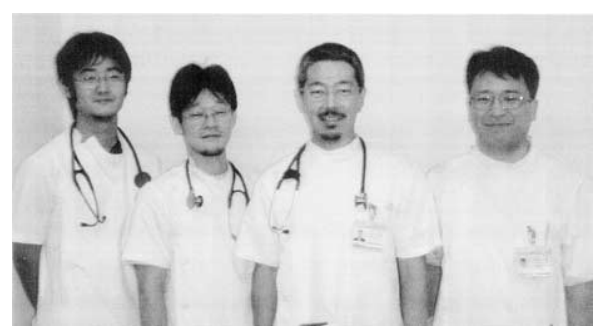

Katayama, Kawamoto, Izutani, Yoshitatsu (left to right)
$\mathrm{M}$ itral valve repair is a widely accepted procedure that now allows reconstruction in most patients with mitral regurgitation. ${ }^{1}$

Techniques in repair, such as quadrangular resection, sliding plasty, annular plication, and annuloplasty, are well performed. ${ }^{2}$ Chordal reconstruction through placement of artificial chordae is also one of the techniques for repair of the prolapsed mitral leaflet to correct elongated chordae or replace ruptured chordae, causing mitral regurgitation. ${ }^{3}$ In placing artificial chordae, adjustment of chordal height is a key for successful mitral valve repair. ${ }^{4}$ Even the surgeon recognizes the optimal knotting position: overaggressive sliding of knots might happen when tying the suture because manual hand tying causes poor visualization of the knots as a result of the small and deep working place involved in the mitral valve procedure. We used a classical knot-tying device to avoid critical knot sliding and to obtain better

From the Division of Cardiovascular Surgery, National Hospital Organization Kure Medical Center, Hiroshima, Japan.

Received for publication Sept 2, 2004; accepted for publication Sept 22, 2004.

Address for reprints: Hironori Izutani, MD, PhD, Division of Cardiovascular Surgery, National Hospital Organization Kure Medical Center, 3-1 Aoyama-cho, Kure, Hiroshima 737-0023, Japan (E-mail: izutani@kurenh.go.jp).

J Thorac Cardiovasc Surg 2005;129:1184-6

$0022-5223 / \$ 30.00$

Copyright $\odot 2005$ by The American Association for Thoracic Surgery

doi:10.1016/j.jtcvs.2004.09.026 visualization for the surgeon and the assistants in performing chordal reconstruction procedures.

\section{Technique}

The device was developed by Dr Hideo Sakihara in 1935 at the former National Kure Hospital in Japan and was manufactured by Senko Medical Instrument Manufacturing Company (Tokyo, Japan). ${ }^{5}$ This device was initially designed for thoracic surgery, especially for operations of the hilar pulmonary vessels because of a deep and narrow surgical field. It has been used mostly in the fields of general surgery, gynecology, and thoracic surgery in Japan. This device is made of metal, and it can be simply autoclaved for regular reuse.

The surgeon holds the device in one hand, makes a knot in the suture, pushes down the knot, and then pulls both ends of the suture with the other hand (Figure 1). The surgeon simply repeats the same maneuver and makes sure the knots are tightened. The surgeon and his or her assistants are able to see the tying process and make sure of the correct position of the knots at all times, even in a deep and narrow surgical field. Therefore, the use of this device makes the surgeon comfortable in deep knot tying.

In our standard procedure for mitral valve repair requiring median sternotomy, left atriotomy was carried out after establishment of cardiopulmonary bypass and cardioplegic arrest. After exposing the mitral valve, chordal reconstruction was performed in the present case with anterior mitral valve leaflet prolapse (Figure 2, A). A pledget-supported double-needled CV-5 polytetrafluoroethylene suture (W. L. Gore \& Associates, Inc, Flagstaff, Ariz) was placed on the anterolateral papillary muscle, and the suture was tied with the device. Then both ends of the suture were placed on the anterior leaflet (Figure 2, B) and tied with the same device 

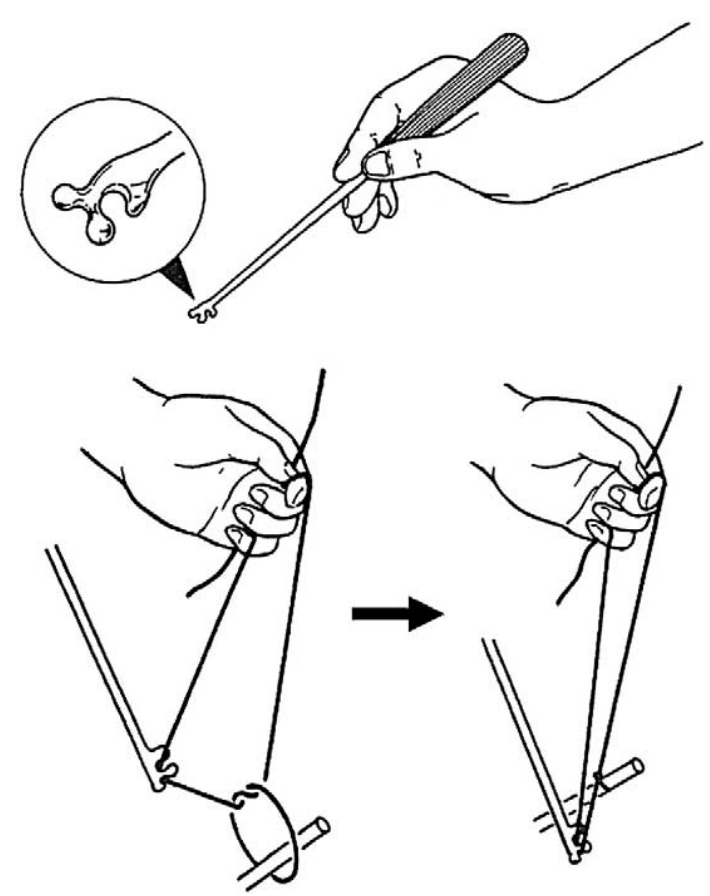

Figure 1. The schemes of the knot pusher and its manipulation. Holding the device with one hand, the knot is pushed down after making a knot in the suture, and then the surgeon pulls both ends of the suture with the other hand. The surgeon simply repeats the same maneuver for secure knot tying. to avoid sliding the knots (Figure 2, C). The position of the knots was well visualized during tying manipulation. After ring annuloplasty, the mitral valve repair was completed (Figure 2,D).

\section{Discussion}

This device has been used in Japan for many years but has not been introduced to other countries. It is not designed for endoscopic procedures. Therefore the device is not too long for direct vision surgery, unlike an endoscopic knot pusher, and can be simply autoclaved for regular reuse. The unique design of the distal tip securely holds knots when pushing down slip knots without having to thread the suture through the knot pusher. The device can be easily set on the suture or released from the suture to allow the surgeon to tie multiple knots quickly and simply. The surgeon simply needs to learn how to use one hand to hold the device and allow the other hand to maintain control of both suture strands at all times.

It is sometimes difficult to tie a suture on the papillary muscle because of the deep and narrow surgical field present when performing artificial chordal replacement. Moreover, it is not easy to keep the optimal knot position on the suspended mitral valve leaflet during hand tying. The use of this device for chordal reconstruction is very reasonable because of its characteristics; however, there was no previous application in the field of cardiac surgery. Our experience showed that this device was suitable for not only tying deep sutures on the papillary muscle but also for accurate chordal height adjustment in artificial chordal replacement for mitral valve repair.

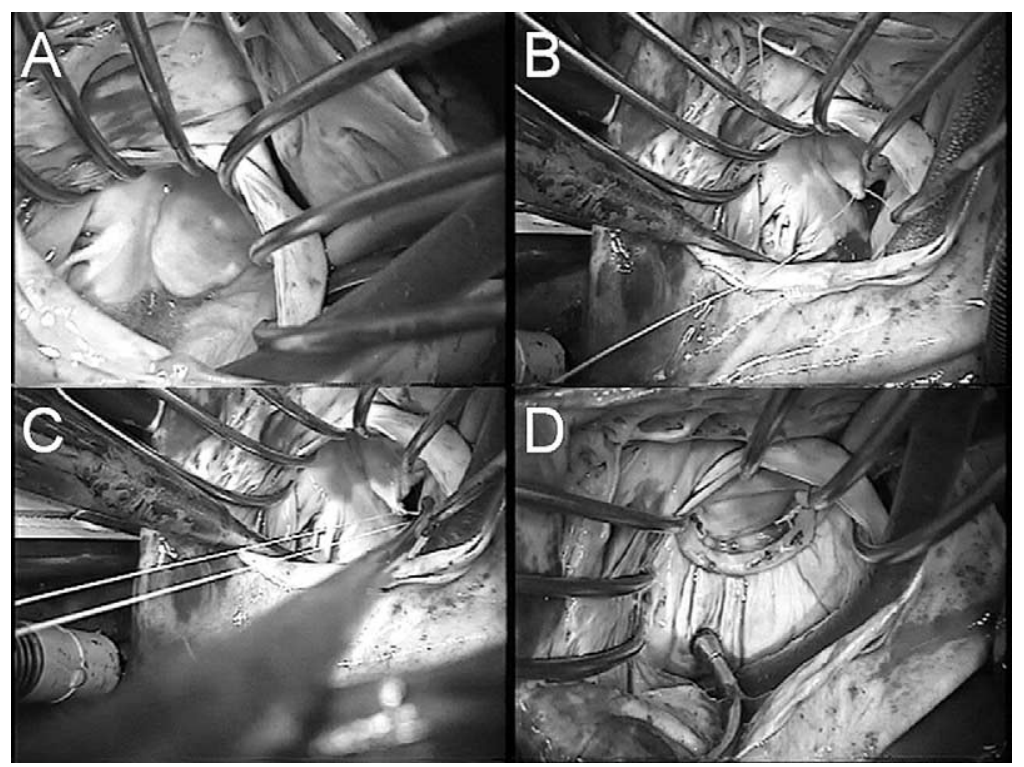

Figure 2. The mitral valve with anterior leaflet prolapse was exposed $(A)$. The chordal replacement sutures were placed on the anterior leaflet $(B)$ and tied with the device $(C)$. The mitral valve repair was completed after ring annuloplasty (D). 


\section{References}

1. Okada Y, Nasu M, Takahashi Y, Handa N, Fujiwara H, Shinkai M, et al. Late results of mitral valve repair for mitral regurgitation. Jpn J Thorac Cardiovasc Surg. 2003;51:282-8.

2. Rankin JS, Orozco RE, Addai TR, Rodgers TL, Tuttle RH, Shaw LK, et al. Several new considerations in mitral valve repair. J Heart Valve Dis. 2004;13:399-409.
3. David TE, Omran A, Armstrong S, Sun Z, Ivanov J. Long-term results of mitral valve repair for myxomatous disease with and without chordal replacement with expanded polytetrafluoroethylene sutures. $J$ Thorac Cardiovasc Surg. 1998;115:1279-85.

4. Adams DH, Kadner A, Chen RH. Artificial mitral valve chordae replacement made simple. Ann Thorac Surg. 2001;71:1377-8.

5. Sakihara H. Sakihara-type deep vascular ligation apparatus. Surg Today. 1997;27:680-1.

\section{How to avoid traction to a pedicled internal thoracic artery graft}

\author{
Franziska H. Bernet, MD, Martin T. R. Grapow, MD, and \\ Hans-Reinhard Zerkowski, MD, FETCS, Basel, Switzerland
}

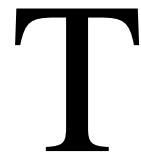

he left internal thoracic artery (LITA) is the most important conduit for coronary artery bypass grafting. ${ }^{1}$ Its application is an independent predictor of late survival, and therefore the LITA should be used in almost all patients. ${ }^{2}$ However, which harvesting technique has more advantages is still unclear. ${ }^{3,4}$ In our institution we routinely performed pedicled LITA grafting to avoid deprivation of the vaso vasorum, innervation and lymphatic and venous drainage.

We present our experience with a technique, first described in 1997 by Rao and colleagues, ${ }^{5}$ to perform a tension-free LITA graft to the left anterior descending artery (LAD).

\section{Technique}

The coronary artery bypass grafting procedure is carried out under standardized conditions concerning surgical management delivery of anesthesia. As usual, we graft the LAD with the pedicled LITA. Before completion of the distal anastomosis, the pericardium is divided with an inversed T-shaped slit to enable a tension-free position of the graft. In case of traction caused by hyperinflated lungs, we additionally create a slit in the apical segment of the upper lobe during arrested ventilation by using an Endo GIA Universal stapler (Autosuture; Tyco Healthcare, Mansfield, Mass) with a double-breasted self-cutting clip suture of 45 or $60 \mathrm{~mm}$ in length. The deflated lung is stabilized with 2 atraumatic clamps, allowing a gentle traction toward the surgeon. The stapler is preliminarily stretched between these 2

\footnotetext{
From the Division of Cardiothoracic Surgery, University Hospital Basel, Basel, Switzerland,

Received for publication Oct 4, 2004; accepted for publication Oct 12, 2004.

Address for reprints: Franziska Bernet, MD, Division of Cardio-Thoracic Surgery, University Hospital Basel, Spitalstrasse 21, 4031 Basel, Switzerland (E-mail: bernetf@uhbs.ch).

J Thorac Cardiovasc Surg 2005;129:1186-7

$0022-5223 / \$ 30.00$

Copyright $\odot 2005$ by The American Association for Thoracic Surgery doi:10.1016/j.jtcvs.2004.10.013
}

clamps, and after verifying the correct position, the cut is released. After restarting ventilation and weaning from cardiopulmonary bypass, the

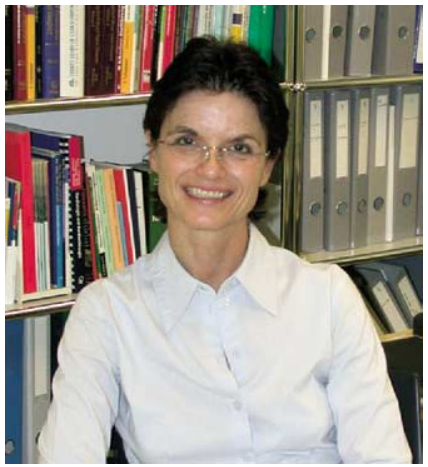

Dr Bernet pedicled LITA conduit is run through the resulting fissure and disappears inside the slit, lying in a straight line to the LAD without kinking (Figure 1). Between 2000 and 2003, 35 (2.4\%) of 1451 patients undergoing isolated coronary artery bypass surgery were treated with the above technique. Eighty percent $(n=28)$ of these patients had a history of severe chronic obstructive pulmonary disease with emphysema. All patients had an uneventful intraoperative and postoperative course. No history of persistent pulmonary

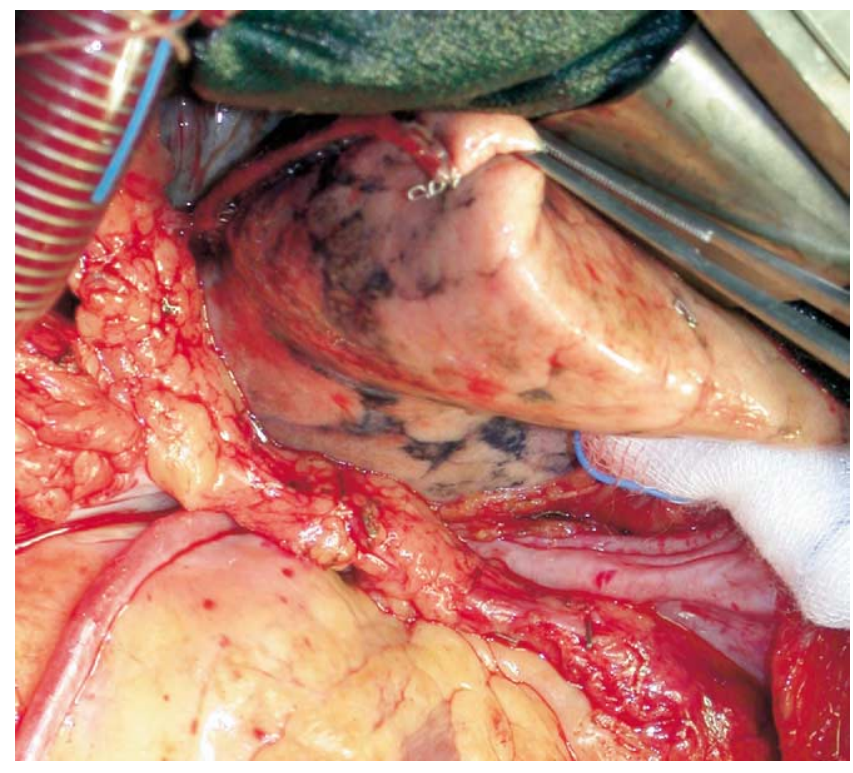

Figure 1. After restarting ventilation, the pedicled LITA is running in a straight line through the fissure of the slit upper lung lobe. 